\title{
The Development of Language in Twins
}

\section{The Development of Twins: Their Resemblances and Differences ${ }^{1}$}

\author{
Ella J. DAY
}

\section{INTRODUCTION}

$\mathbf{M}$ AN'S curiosity in the unusual has led him into many fields of adventure. Twins, constituting about one per cent of the births according to Davenport (3) are both so rare and so different that science has for a long time been very curious about their origin, their resemblances and their differences. The dispute as to the relative importance and effects of heredity and environment in moulding human nature dates back to the ancient Greek philosophers and scientific workers always have felt that twins presented a special opportunity for making such studies.

Newman's (16) investigations on the star fish and the Texas armadilla as

1 From the Institute of Child Welfare, the University of Minnesota. The Development of Language in Twins, Part I, A Comparison of Twins and Single Children appeared in Child Development (Vol. 3, No. $3)$. It reported the language development of 80 pairs of 2 to 5 year old twins and compared their development with that of the single children reported by D. A. McCarthy (13) in The Language Development of the Preschool Child. McCarthy's method and technique were repeated throughout. The tables of Part 1 and 2 are numbered continuously. well as his more recent studies of twins, point unquestionably to the fact that there are 2 types of twins. The identical or monozygotic twins arise from the splitting of a single zygote while the fraternal or dizygotic twins arise from the simultaneous development of two zygotes. The psychological studies of twins beginning with that of Galton (4) in 1883 also give evidence of the two types of twins, in that they show a greater degree of resemblance in both physical and mental traits in identical twins than in fraternal twins. Thorndike (19) in 1905 disputed this fact. The later investigations of Merriman (14), Lauterbach (12), Gesell, $(5,6)$, Muller (15) and Wingfield (22) however have all supported the theory of the monozygotic origin of identical twins.

This investigation, though undertaken primarily to compare language development in twins with that in single children, also obtained sufficient information in regard to the twins studied to determine fairly accurately whether or not they were identical or fraternal twins. With these data at hand, the three types of twins, identical, like-sex fraternal and unlike-sex fraternal were compared as to resem- 
blances and differences in language attainment, mental test performance and certain physical characteristics.

\section{Subjects}

Eighty pairs of twins, 20 at each age level, 2, 3, 4, and 5 years, were selected on the basis of sex and occupational class. Like-sex twins were selected in preference to unlike-sex twins in an effort to obtain a larger number of identical twins in the group. Table $5,{ }^{2}$ shows the distribution of cases by age, sex and type of twin.

The percentage of both identical (23.75) and unlike-sex twins (28.75) is foreign language spoken in the home; policy of the family with regard to speech of the twins; age, sex, and speech of the twins' playmates; leadership and emotional habits of the twins; and whether the family considered them identical.

Specific information obtained on each twin included physical defects, sensory handicaps, serious illnesses, age of walking, talking, first tooth, handedness, thumb sucking, and other nervous habits, play interests, selfhelp in eating, dressing and toilet habits, and hair and eye color.

In addition to this information

TABLE 5

Distribution of cases by age, sex and type of twin

\begin{tabular}{|c|c|c|c|c|c|c|c|c|c|c|}
\hline \multirow{2}{*}{ TYPE OF TWIN } & \multicolumn{2}{|c|}{2 YEARS } & \multicolumn{2}{|c|}{3 YEARS } & \multicolumn{2}{|c|}{4 YEARS } & \multicolumn{2}{|c|}{5 YEARS } & \multicolumn{2}{|c|}{ TOTAL } \\
\hline & Boys & Girls & Boys & Girls & Boys & Girls & Boys & Girls & Pairs & $\begin{array}{c}\text { Per } \\
\text { cent }\end{array}$ \\
\hline Like sex identical.. & 8 & 10 & 2 & 4 & 2 & 6 & 4 & 2 & 19 & 23.75 \\
\hline Fraternal......... & 8 & 6 & 10 & 8 & 12 & 10 & 10 & 12 & 38 & 47.50 \\
\hline Unlike sex. . & 4 & 4 & 8 & 8 & 5 & 5 & 6 & 6 & 23 & 28.75 \\
\hline
\end{tabular}

low for a representative sampling of the twin population. The like sex fraternal group is proportionately high.

\section{Procedure}

Information in regard to the development, likenesses and differences of the twins was obtained largely by means of a questionnaire. This was filled out in consultation with the mother at the same time that the language record was obtained.

Information about the family included parents' birthplaces, education, and occupation; names, and ages, and age of talking of other children;

2 Tables are numbered consecutively from Part 1. records were obtained, where possible, from the hospital or physician, as to the number of placentae reported at the delivery of the twins. Later, when the question arose as to the possible relationship of prematurity of birth to the apparent mental retardation of the twins, a questionnaire was sent to the mother, asking for the following information: Order of birth of the twins, whether or not the twins were born at full term and if not how much they varied from it, whether or not twinning had appeared in any of the relatives of the mother or the father. Seventy of the 80 parents, or 87.5 per cent replied to this questionnaire. 
THE MENTAL DEVELOPMENT OF THE TWINS

The language retardation of the twins, evident in every method of analysis, suggests at once, the possibility of a similar mental retardation. Merriman was the first to use the present day intelligence test as a device for measuring mental ability of twins and so he was the first one to report I.Q.'s on a large group. Although he found the mean I.Q. of 105 pairs to be 96 , he assumed that the slight retardation was due to selection were attempted but a satisfactory test was not obtained. The remainder of the group failed to coöperate to the extent of allowing the tests to be given. The range of I.Q.'s for the twin group was from 59 to 138 .

Table 6 shows the mean I.Q.'s by age and sex of the twins and singletons.

It may be seen, as has been pointed out previously, that the twin group is consistently below average, with the exception of the two year old and five year old girls. The singleton group, on the contrary, are slightly

TABLE 6

Mean I.Q. of twins and singletons by age and sex

\begin{tabular}{|c|c|c|c|c|c|c|c|c|}
\hline \multirow{3}{*}{ C.A. } & \multicolumn{5}{|c|}{ TWINS } & \multicolumn{3}{|c|}{ SINGLETONS (MC CARTHY) } \\
\hline & \multicolumn{2}{|c|}{ Boys } & \multicolumn{2}{|c|}{ Girls } & \multirow{2}{*}{$\stackrel{\text { All- }}{\text { Mean I.Q. }}$} & \multirow{2}{*}{$\begin{array}{l}\text { Boys-- } \\
\text { Mean I.Q. }\end{array}$} & \multirow{2}{*}{$\underset{\text { Mean I.Q. }}{\text { Girls- }}$} & \multirow{2}{*}{$\underset{\text { Mean I.Q }}{\text { All- }}$} \\
\hline & $\begin{array}{c}\text { Number of } \\
\text { cases }\end{array}$ & Mean I.Q. & $\begin{array}{l}\text { Number } \\
\text { of cases }\end{array}$ & Mean I.Q. & & & & \\
\hline $\begin{array}{c}\text { years } \\
2\end{array}$ & 14 & 89.0 & 11 & 103.0 & 95.0 & 102.4 & 109.4 & 106.9 \\
\hline 3 & 15 & 95.0 & 18 & 93.0 & 94.0 & 100.5 & 97.7 & 99.3 \\
\hline 4 & 18 & 90.0 & 17 & 92.0 & 91.0 & 101.8 & 103.8 & 103.8 \\
\hline 5 & 14 & 95.0 & 16 & 101.0 & 98.0 & & & \\
\hline
\end{tabular}

of cases and was not to be interpreted as indicating mental inferiority of twins as a whole. Wingfield (22) on the contrary, concluded from his study, that twins were from 1 to 2 per cent below average in intelligence.

\section{INTELLigence of the Twins}

The twins of the present study were given the Minnesota Pre-school Scale ${ }^{3}$ as described in Part 1. Test scores were obtained on only 123 of the 160 children. In a few more cases, tests

${ }^{3}$ This scale was in the process of standardization at the time this investigation was made. superior, except at the three year age group which is approximately average. The tests used in the two instances were not the same. The singletons were given the Kuhlman-Binet test and the twins were given the Minnesota Pre-school Scale (9). However this scale is composed largely of the individual tests from the Kuhlman and Stanford-Binet tests; hence the actual items of each test do not differ greatly. Boys are inferior to girls at every age in both groups, except at three years. Since the selection of the two groups is so nearly identical, the evidence points rather directly toward slight inferiority of the twin 
group in general intelligence as it was measured.

Not only are the upper occupational groups superior to the lower occupational groups in each cases, but the lower occupational group of singletons is superior to the upper occupational group of twins. A similar situation was apparent in regard to mean length of language response. The slight differences in the percentage of each population, taken from the upper and lower occupational groups, favors the twin group. Exactly 50 per cent of the twin group fall in the three upper cluding the present study, represent a total population of 737 twin children of 368.5 pairs. The range in age is from two to about sixteen years. The intelligence tests used have been standard tests. Only one mean I.Q. in the table is as high as 100 or above, and that is for the 50 pairs of identical twins examined by Freeman. In addition to those data, the Lauterbach data give a mean I.Q. of 95 for that twin group. This adds about 200 pairs of twins to the population considered, making a total of 568 pairs. The mean I.Q. for this entire group

TABLE 7

Mean I.Q. of like-sex and unlike-sex twins as found by the different investigators

\begin{tabular}{|c|c|c|c|c|c|c|c|c|c|c|}
\hline & \multicolumn{2}{|c|}{ DAY } & \multicolumn{2}{|c|}{ WINGFIELD } & \multicolumn{2}{|c|}{ FREEMAN } & \multicolumn{2}{|c|}{ MERRIMAN } & \multicolumn{2}{|c|}{ TOTAL } \\
\hline & $\begin{array}{c}\text { Num- } \\
\text { ber }\end{array}$ & I.Q. & $\begin{array}{c}\text { Num- } \\
\text { ber }\end{array}$ & I.Q. & Num- $_{\text {ber }}$ & I.Q. & $\begin{array}{c}\text { Num- } \\
\text { ber }\end{array}$ & I.Q. & $\begin{array}{c}\text { Num- } \\
\text { Ner }\end{array}$ & I.Q. \\
\hline Like sex. & 88 & 93.5 & & & 200 & 98.8 & & & 288 & 97.2 \\
\hline Identical... & 27 & 99.7 & 90 & 99.0 & 100 & 101.6 & 44 & 98.0 & 261 & 99.9 \\
\hline Fraternal. & 61 & 90.8 & 62 & 92.9 & 100 & 96.1 & 90 & 96.2 & 313 & 94.5 \\
\hline Unlike sex. . & 35 & 96.2 & 52 & 98.6 & & & 76 & 94.7 & 163 & 96.3 \\
\hline All fraternal. & 96 & 92.8 & 114 & 95.7 & & & 166 & 95.5 & 376 & 94.9 \\
\hline All twins..... & 123 & 94.3 & 204 & 97.2 & 200 & 98.8 & 210 & 96.0 & 737 & 96.8 \\
\hline
\end{tabular}

groups as compared with 47.1 per cent of the singleton group.

The most interesting evidence in regard to the intellectual inferiority of twins may be seen by a comparison of the finuings of the various twin studies. (See table 7) Here the data from the Wingfield, Freeman ${ }^{4}$ and Merriman studies have been assembled and to some extent reworked, from their original data, to get the desired means. This group of studies, in-

${ }^{4}$ Investigation now under way in collaboration with Newman and others at University of Chicago. These figures came from mimeographed notes presented by Dr. Freeman at a lecture. of 568 pairs of twins is 96.3 . Such a sampling as this, showing consistent mean I.Q.'s from 1 to 6 points below the average I.Q. of 100 , for the population as a whole, is surely sufficient evidence to confirm Wingfield's conclusion, that twins are, as a group, slightly below the average in intelligence as measured.

\section{COMPARISON OF THE INTELLIGENCE OF} IDENTICAL LIKE-SEX

\section{Fraternal and Unlike-sex twins}

Dr. Freeman in making a preliminary report of the twin study being conducted at the University of Chi- 
cago, called the attention of the writer to the possible differences in mean I.Q. between identical and fraternal twins. In order to obtain such information in regard to the groups studied, by the other investigators, their original data were worked over. Wingfield and Freeman distinguish their twins as identical, like-sex fraternal or unlike-sex. For the Merriman study, a group denoted, "reported as very similar" in appearance were selected by the writer as the nearest approach to an identical group. The necessary original data for the Lauterbach study could not be obtained. In the Thorndike group, 11 pairs, who from the data on physical measurements appeared to be most nearly alike were selected as possible identical twins. Those data did not give I.Q.'s but the mean deviation from the mean of the composite score, for all tests given, was used as denoting the relative standing of the various types of twins.

Table 7 shows that in every group the identical twins were superior to the fraternal twins and most nearly approached the average of the population as a whole. The total sampling represented is about 130 pairs. Merriman shows a lower mean I.Q. for the identical group than is shown by any other study. It must be remembered, however, that this group is less carefully selected and so very probably includes some fraternal twins. Moreover, his fraternal group very possibly includes some identical twins. The fraternal group, including like and unlike-sex twins, drops from 2.5 to 7.0 points below the identical group in
I.Q. This group comprises 238 pairs of twins.

In the Thorndike data the differences are in the same direction. (See table 8.) The fraternal group score slightly below the mean for the entire group and the identical twins score considerably above this mean.

If the data presented by these various studies are on a representative sampling of twins, the consistency of the findings is evidence of a real difference in intelligence between identical and fraternal twins. The cause

TABLE 8

Mean deviation score of twins (Thorndike)

\begin{tabular}{|c|c|c|}
\hline & $\begin{array}{c}\text { NUMBER } \\
\text { OF } \\
\text { CASES }\end{array}$ & $\begin{array}{c}\text { MEAN } \\
\text { DEVIATION } \\
\text { SCORE }\end{array}$ \\
\hline Like sex: & & \\
\hline Identical. & 22 & +791.77 \\
\hline Fraternal. & 34 & -26.35 \\
\hline Unlike sex.......... & 14 & -126.57 \\
\hline All fraternal........... & 48 & -55.58 \\
\hline
\end{tabular}

for such a difference brings up biological problems of great interest. Two of the factors suggested, as possibly entering into such a difference, are the mean occupational class represented by each group and the question of prematurity. Such data were available only for the twins of this study and are presented in table 9.

The occupational class differences favor the identical twins by .3 of an occupational class. It would be interesting to know whether or not the tendency for twins to develop from a single zygote is more prevalent among the upper classes than in the lower classes. The sampling is too small in 
the present study to make sure that this difference is not due to selection. It is to be hoped, that in the future investigators will note the occupational class of the subjects.

The Goodenough (8) evaluation of the Kuhlman-Binet test was based upon 300 cases very carefully selected from the standpoint of occupational class. Goodenough says, "The differences between the mean I.Q. earned on the first examination by the children of parents belonging to the professional classes, and the correspond-

\section{TABLE 9}

Mean I.Q., occupational class and period of gestation like-sex and unlike-sex twins

\begin{tabular}{|c|c|c|c|}
\hline TWINS & $\begin{array}{l}\text { MEAN } \\
\text { I.Q. }\end{array}$ & $\begin{array}{c}\text { OCCUPA- } \\
\text { TIONAL } \\
\text { CLASS }\end{array}$ & $\begin{array}{l}\text { PERIOD } \\
\text { OF } \\
\text { GESTA- } \\
\text { TION }\end{array}$ \\
\hline & & & weeks \\
\hline \multicolumn{4}{|l|}{ Like sex: } \\
\hline Identical. & 99.7 & 3.4 & 36.1 \\
\hline Fraternal. & 90.8 & 3.9 & 38.5 \\
\hline Unlike sex... & 96.2 & 3.5 & 39.9 \\
\hline All fraternal. & 92.8 & 3.7 & 39.2 \\
\hline
\end{tabular}

ing rating for the children of day laborers amounts to approximately one and one-fourth standard deviations of the total distribution of I.Q.'s for the entire group." Goodenough's findings in this regard are in close agreement with the results of the army intelligence tests and those of Haggerty and Nash (11) based upon an examination of 6,688 New York State School children. The difference of .3 of an occupational class found in this study between the identical and fraternal groups, is no doubt a factor in causing the differences found be- tween these groups in I.Q. It is, nevertheless, a question as to whether it is entirely accountable for the difference.

It is a well known fact that twin births constitute a large proportion of the premature births. This is one factor in their high rate of mortality at birth. Capper (1) in an investigation of 437 immature infants, found that 72 per cent of them were born prematurely. Fourteen per cent of those born prematurely were twins. The mean period of gestation for 68 pairs in the present study was 38.4 weeks or 269 days. This is not apparently a startling variation since Capper says, "In obstetrics a mature infant is one born at term, i.e., at the end of from 270 to 290 days, irrespective of the degree of the development of the baby.'"

Table 9 shows that the identical group have the lowest mean period of gestation and are approximately one month premature. They are, however, the group with the highest mean I.Q. A correlation (Pearsonian $r$ ) of $+.03 \pm .067$ was obtained between I.Q. and the period of gestation for 102 twins. The correlation between birth weight and the period of gestation was found to be $-.44 \pm .054$ and between birth weight and I.Q. $+.05 \pm .062$. Since there is little relationship between, either the period of gestation and I.Q. or the birth weight and I.Q., prematurity cannot be a very significant factor in causing the differences in I.Q. between identical and fraternal twins. Gesell (7), in discussing the growth of the premature infant, says, "The maturation of the 
central nervous system is perhaps least affected by the condition of prematurity. The head of the premature infant continues to grow in size at a relatively normal rate, even when his general bodily development is distinctly subnormal."

\section{EFFECT OF LANGUAGE UPON THE} MENTAL TEST SCORE

Thirteen of the 29 individual tests included in the Minnesota Pre-school Scale at this time, required a verbal response. Since the twins as a group were 6 points below average in I.Q., the question arose as to whether the intelligence test score had not been reduced by the twins' handicap in language. In order to check this point, the four year old group, which had a lower mean I.Q. than any other age group (91.), were matched with a control group of single children. Mental tests had been obtained on 35 of the four year old twins. These were matched as closely as possible with other cases, who had been given the same test. They were matched in regard to total test score, chronological age at time of testing, sex, and occupational class.

Table 10 shows the means of the various aspects matched, which were found for the two groups. It also shows the mean raw scores and percentage scores, determined separately, for the 13 verbal and the 16 non-verbal test items. These could not agree much more closely. It seems to the writer to show that the Minnesota Scale requires a minimum of language, as it was planned to do. At least, single children, who it has already been pointed out, have superior lan- guage ability, did not in this instance use their language ability any more effectively than did the twins. The language retardation of these four year old twins, does not seem to have been a factor in reducing the total test score and thus lowering the I.Q. It may be pointed out, however, that

TABLE 10

Mean intelligence test score, age and occupational class of four year old twins and control group

\begin{tabular}{|c|c|c|}
\hline & $\begin{array}{l}\text { TWINS- } \\
\text { MEANS }\end{array}$ & $\begin{array}{l}\text { SINGLE- } \\
\text { TON (CON } \\
\text { TROL) - } \\
\text { MEANS }\end{array}$ \\
\hline Occupational class. . & 3.9 & 4.1 \\
\hline Chronological age*. & $4-2-3$ & $4-2-7$ \\
\hline Total test score..... & 103.37 & 103.60 \\
\hline Raw verbal score...... & 47.4 & 47.0 \\
\hline Raw non-verbal score.. & 56.0 & 56.6 \\
\hline 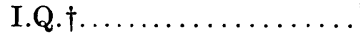 & 90.7 & 93.6 \\
\hline Percentage verbal score. & 46.3 & 45.4 \\
\hline $\begin{array}{l}\text { Percentage non-verbal } \\
\text { score } \ldots \ldots \ldots \ldots \ldots \ldots\end{array}$ & 53.7 & 54.6 \\
\hline
\end{tabular}

* C.A. is stated in years, months and days.

$\dagger$ The apparent discrepancy in the differences found in I.Q., although the total test score and C.A. are the same is due to the fact that as the Minnesota Scale was still in process of standardization, the raw point score had not yet been transferred into equivalent scale values.

the test did not give an opportunity for the maximum use of language.

The relation between the language development and intelligence may be seen by the series of correlations presented in table 11. The Pearson product moment method of correlation was used.

It may be seen, that the McCarthy four year old singletons show a small positive correlation between length of 
response deviation from the mean and I.Q. whereas the twins, of this age, show practically no correlation. Twins at 2, 3, and 5 years, however, show similar correlations of +.43 between mean length of response and
2 years 14.75, 3 years 12.83 , 4 years $9.19,5$ years 14.00 .

The four year old group, for some reason, shows a fairly high negative correlation ( -.57$)$ between the total score on the intelligence test and the

TABLE 11

Correlations between measures of language development and measures of intelligence

\begin{tabular}{|c|c|c|c|c|c|c|}
\hline \multirow{2}{*}{ TRAITS CORRELATED } & \multicolumn{3}{|c|}{ Twins } & \multicolumn{3}{|c|}{ SINGLETONS } \\
\hline & $\begin{array}{l}\text { Number } \\
\text { of cases }\end{array}$ & $r$ & P.E. & $\begin{array}{c}\text { Number } \\
\text { of cases }\end{array}$ & $r$ & P.E. \\
\hline $\begin{array}{c}\text { I.Q. and mean length response } 2 \\
\text { years } \ldots \ldots \ldots \ldots \ldots \ldots \ldots \ldots\end{array}$ & 25 & +.42 & \pm .11 & & & \\
\hline $\begin{array}{r}\text { I.Q. and mean length response } 3 \\
\text { years } \ldots \ldots \ldots \ldots \ldots\end{array}$ & 33 & +.43 & \pm .09 & & & \\
\hline $\begin{array}{r}\text { I.Q. and mean length response } 4 \\
\text { years } \ldots \ldots \ldots\end{array}$ & 35 & -.07 & \pm .11 & & & \\
\hline $\begin{array}{l}\text { I.Q. and mean length response } 5 \\
\text { years } \ldots \ldots \ldots \ldots \ldots \ldots \ldots \ldots \ldots \ldots \ldots \ldots\end{array}$ & 30 & +.43 & \pm .10 & & & \\
\hline Four-year age group: & & & & & & \\
\hline I.Q. and verbal score $\ldots \ldots \ldots \ldots \ldots$ & 35 & +.40 & .10 & & & \\
\hline $\begin{array}{l}\text { I.Q. and non-verbal score } \ldots \ldots \ldots \\
\text { Mean length response and verbal }\end{array}$ & 35 & +.64 & .07 & & & \\
\hline score $\ldots \ldots \ldots \ldots \ldots \ldots \ldots \ldots \ldots$ & 35 & -.04 & .11 & & & \\
\hline $\begin{array}{l}\text { Mean length response and non-ver- } \\
\text { bal score } \ldots \ldots \ldots \ldots \ldots \ldots \ldots\end{array}$ & 35 & -.13 & .11 & & & \\
\hline $\begin{array}{l}\text { Length of response deviation } \\
\text { from mean and I.Q............ }\end{array}$ & 35 & -.08 & .11 & 20 & +.37 & $\pm .13^{*}$ \\
\hline Verbal and non-verbal scores...... & 35 & +.63 & \pm .07 & 35 & +.61 & $\pm .07 \dagger$ \\
\hline $\begin{array}{l}\text { Total test score and per cent verbal } \\
\text { score } \ldots \ldots \ldots \ldots \ldots \ldots \ldots \ldots \ldots \ldots \ldots\end{array}$ & 35 & -.57 & \pm .08 & 35 & +.09 & $\pm .11 \dagger$ \\
\hline $\begin{array}{l}\text { Total test score and per cent non- } \\
\text { verbal score } \ldots \ldots \ldots \ldots \ldots \ldots \ldots\end{array}$ & 35 & +.55 & \pm .08 & 35 & +.08 & $\pm .11 \dagger$ \\
\hline Five-year age group: & & & & & & \\
\hline 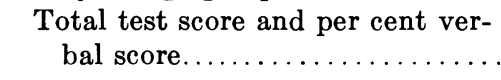 & 30 & +.01 & \pm .12 & & & \\
\hline
\end{tabular}

* Mc Carthy singletons.

$\dagger$ Control four-year old singletons.

I.Q. The lower, or practically zero, correlation of the 4 year old group, in this instance, is probably affected by the smaller standard deviation of I.Q.'s. The standard deviations of the distribution of I.Q.'s are as follows: percentage of verbal score. Both the control group of singletons and the five year old twins show approximately a negative correlation between these same scores. It appears to be true, for these four year old twins, that 
the lower the proportion of verbal score, the higher the total test score although such is not the case for five year old twins. It is open to question then, as to whether the relationship found in the four year old twins is to be interpreted as typical for twins in general, or whether it may be attributed to some phenomenon of this particular group of twins or what is perhaps more probable, of the test used.

COMPARATIVE RETARDATION OF TWINS

IN LANGUAGE DEVELOPMENT AND GENERAL INTELLIGENCE

In order to compare the language retardation of the twins with their retardation in general intelligence, the mean length of response was converted into a language quotient. To do this the mean length of response of singletons for each age group was assumed as 100 or average. This involves error, since the McCarthy study is based upon only 20 children at each age. However, no other data were available.

The language age was determined by the following formula:

$$
\text { S : "C.A." : : T : X }
$$

"S" = the mean length of response for the singletons of a given age. ${ }^{5}$

"C.A." = the given age.

5 This figure (4.7) at 5 yrs. was taken from the Smith investigation. Her mean lengths of response at all ages agreed closely with the McCarthy findings. Smith, M.E. An Investigation of the Development of the Sentence and the Extent of Vocabulary in Young Children. Univ. of Iowa, Studies in Child Welfare, 3, No. 5. Iowa City, 1926. $92 \mathrm{pp}$.
" $\mathrm{T} "=$ the mean length of response of the twins for the given age.

" $\mathrm{X} "=$ the language age.

$\frac{\mathrm{X}}{\mathrm{C} . \mathrm{A}}=$ the language quotient (L.Q.).

Table 12 shows the comparative retardation of twins in language development and general intelligence in terms of L.Q. and I.Q. The language retardation is so significantly greater, that factors other than "below average general intelligence" must be responsible for it. The language quotient decreases rapidly as age increases in spite of the fact that the intelligence quotient does not. Nevertheless, this increasing difference is not accompanied by a decreasing relationship between the two factors since the correlations between mean length of response and I.Q. show no consistent trend with age.

The twin situation differs markedly from the situation of a single child in but one respect and that is companionship. This difference begins in fetal life and is an environmental factor. It will have to be left for the biologists to tell whether or not, the development of two embryos may limit or reduce the inherited traits, and in what particulars. The differences between the mental ability of identical and fraternal twins suggests a nutritional difference in embryo. Since there are twice as many fraternal twins as identical twins, they would tend to pull down the mean I.Q. for twins as a whole, keeping it below 100 . Aside from the possible inheritance of imperfect physiological factors concerned with speech, it seems more probable to expect the environmental factor to 
have a limiting effect. One surely could not learn as much or as rapidly, from companionship with an individual so nearly on his own plane, as from one who was in advance. Satisfactions from this companionship may be adequate to the twin, whereas the single child may be motivated to gain his satisfactions from a wider field.

\section{THE RESEMBLANCE OF THE TWINS}

Basis for the selection of identical twins

The information obtained about the placentae proved to be too indefinite, in most cases, to be reliable. Like-

\section{The development of the twins}

The prematurity of the twins was discussed in connection with its relation to mental development. The mean birth weight was 2595.46 grams with a mean period of gestation of 269 days. The birth weight figures were taken from the mother's report. The hazard of this birth weight may be seen by Capper's statement, that of the 437 records of immature infants 145 weighed from 2,001 to 2,500 grams. The mortality of this group was 32 per cent by 6 years. The average birth weight for the popula-

TABLE 12

Comparative retardation of twins in language development and in general intelligence

\begin{tabular}{l|c|c|c|c}
\hline & \multicolumn{4}{|c}{ MEAN } \\
\cline { 2 - 5 } & 2 years & 3 years & 4 years & 5 years \\
\hline Intelligence quotient......................... & 95.0 & 94.0 & 91.0 & 98.0 \\
Language quotient....................... & 83.5 & 73.7 & 68.2 & 68.0 \\
\hline
\end{tabular}

ness in hair and eye color and general appearance were found to be a more adequate basis for determining the identical twins. There were but five doubtful cases. One pair of girls, were finally classed as identical, as the only difference in them was a slight difference in size. The other four were all classed as fraternal due to slight differences in appearance.

The proportion of each type of twin having both identical hair and eyes is shown in Table 13. In approximately 50 per cent of the entire group these were similar although in only about 24 per cent, the identical group, was the appearance of the children also identical.
TABLE 13

The proportion of twins having identical hair and eyes

\begin{tabular}{|c|c|c|c|}
\hline & $\begin{array}{l}\text { NUM- } \\
\text { BER OF } \\
\text { PAIRB }\end{array}$ & $\begin{array}{c}\text { PER } \\
\text { CENT } \\
\text { OF } \\
\text { TWIN } \\
\text { GROUP }\end{array}$ & $\begin{array}{c}\text { PER } \\
\text { CENT } \\
\text { OF } \\
\text { LIKE } \\
\text { HAIR } \\
\text { AND } \\
\text { EYE } \\
\text { GROUP }\end{array}$ \\
\hline Identical. & 18 & 94.7 & 46.2 \\
\hline Like sex fraternal & 15 & 39.5 & 38.4 \\
\hline Unlike sex....... & 6 & 26.1 & 15.4 \\
\hline All twins........ & 39 & 48.75 & \\
\hline
\end{tabular}

tion as a whole is between 3000 and 3500 grams.

Of the 68 pairs who had older brothers and sisters 42 per cent were reported by the mother as developing 
more slowly physically than the other children, 46 per cent were reported as developing about the same and 12 per cent faster than the older siblings. In the three twin groups, 35 per cent of the identicals developed more slowly than older siblings, 45 per cent of the fraternals were slower, and 39 per cent of the unlike sex.

The development of the twins in learning to talk and walk, and in cutting the first tooth is shown in table 14. The identical group shows a slight minus deviation from the mean in age of talking and walking same direction as the language retardation of the twins found throughout this study the subjectivity of the data and the small number of cases did not warrant further analysis.

Both the twins and their siblings were late in beginning to talk. In consideration, however, of the subjectivity of the data, the fact that the twins began to talk at a later age than their siblings seems to be more significant, in denoting their retardation, than is the comparison with the norm.

The twins appear average in respect to age of walking according to Gesell's

TABLE 14

Mean age of beginning to talk, walk, and cut teeth

\begin{tabular}{|c|c|c|c|c|c|c|}
\hline & \multicolumn{2}{|c|}{ TALKING } & \multicolumn{2}{|c|}{ WALKING } & \multicolumn{2}{|c|}{ CUTTING TEETH } \\
\hline & Mean age & $\mid \begin{array}{c}\text { Deviation } \\
\text {-mean }\end{array}$ & Mean age & $\underset{\text { Deviation }}{\text {-mean }}$ & Mean age & $\mid \begin{array}{c}\text { Deviation } \\
\text {-mean }\end{array}$ \\
\hline Identical........... & $\begin{array}{c}\text { months } \\
15.3\end{array}$ & -1.7 & $\begin{array}{c}\text { months } \\
14.6\end{array}$ & -.3 & $\begin{array}{c}\text { months } \\
8.4\end{array}$ & +.3 \\
\hline Like sex fraternal. & 17.2 & +.2 & 15.1 & +.2 & 9.4 & +1.3 \\
\hline Unlike sex....... & 18.2 & +1.2 & 14.8 & .1 & 7.8 & -.3 \\
\hline All twins.... & 17.0 & & 14.9 & & 8.1 & \\
\hline
\end{tabular}

but a plus deviation (.3) in age of cutting the first tooth. The like sex fraternal group show a plus deviation from the mean in all three activities. The unlike-sex twins show a plus deviation from the mean in age of talking but a minus deviation in the age of walking and of cutting the first tooth. The 68 pairs of twins having older siblings, show a mean age of talking approximately one month (.96 mos.) later than the mean age of talking for the older siblings. These data are based on the mother's report of the ages at which the children first talked, and are therefore subjective. Although the difference lies in the norm. The twins also cut their first teeth within the average time stated, which is 6 to 9 months.

Emotional resemblance. Sixty per cent of all the twins were reported as being different emotionally. However, only 32 per cent of the identical twins were thought to differ in this respect as compared with 72 per cent of the like sex fraternals and 65 per cent of the unlike-sex twins.

Leadership. In 75 per cent of the cases, one twin was reported as showing the qualities of a leader more than the other twin. This was reported as being the case in 37 per cent of the identical twins, 87 per cent of both the 
like-sex and unlike-sex fraternal twins. In the unlike-sex twins the girl was reported as being the leader approximately twice as often as the boy.

Handedness. The handedness of the twins is based upon the mother's report and not upon a test of handedness. Thirty-four or 21.0 per cent of all the twins showed some tendency to left-handedness. Table 15 shows the proportion of each type of twin, who were right-handed, left-handed or ambidextrous.

Of the 34 twins having a tendency one an unlike-sex pair, and one a pair of identical boys.

Newman's theory of the "asymmetry mechanism" and its effect on the degree of likeness found between identical twins assumes that handedness is genetically determined. If this is true, one would expect to find the percentage of left handedness in twins of dizygotic origin equal to that in the population as a whole or about 4 to 5 per cent. Of the 122 fraternal twins in this group, 15 or 12 per cent were positively left handed and twenty-

TABLE 15

Handedness in twins

\begin{tabular}{|c|c|c|c|c|c|c|c|c|}
\hline & \multicolumn{6}{|c|}{ PROPORTION OF ALL TWINS } & \multirow{2}{*}{\multicolumn{2}{|c|}{$\begin{array}{l}\text { PROPORTION OF } \\
\text { TWINS WITH LEFT- } \\
\text { HANDED TENDENCY }\end{array}$}} \\
\hline & \multicolumn{2}{|c|}{ Right } & \multicolumn{2}{|c|}{ Left } & \multicolumn{2}{|c|}{ Both } & & \\
\hline & $\underset{\text { ber }}{\text { Num- }}$ & $\begin{array}{l}\text { Per } \\
\text { cent }\end{array}$ & $\underset{\text { ber }}{\text { Num- }}$ & $\begin{array}{c}\text { Per } \\
\text { cent }\end{array}$ & $\underset{\text { ber }}{\text { Num- }}$ & $\begin{array}{c}\text { Per } \\
\text { cent }\end{array}$ & Number & Per cent \\
\hline Like sex: & & & & & & & & \\
\hline Identical & 29 & 76 & 4 & 11 & 5 & 13 & 9 & 26 \\
\hline Fraternal. & 65 & 86 & 7 & 9 & 4 & 5 & 11 & 32 \\
\hline Unlike sex. & 82 & 80 & 8 & 17 & 6 & 13 & 14 & 42 \\
\hline All twins.. & 126 & 79 & 19 & 12 & 15 & 9 & & \\
\hline
\end{tabular}

to use the left hand, 21 or 62 per cent were boys and 13 or 38 per cent were girls. Twenty-four per cent of the identical twins showed a tendency to use the left hand although only 11 per cent were positively left-handed. Fourteen per cent of the like-sex fraternal group showed such a tendency although only 9 per cent were positively left handed. Thirty per cent of the unlike sex twins inclined in this direction with seventeen per cent definitely left handed. There were only three pairs in which both twins tended to be left handed. One of these was a pair of fraternal girls, five or 20 per cent showed some tendency in that direction. Some other factor peculiar to the twin situation must be operative to increase the percentage to this extent. These data are not sufficiently reliable either in number of cases or in the method of determining handedness to draw any definite conclusions. In general, however, these findings are in agreement with those reported by others. Lauterbach found about 19 per cent of the two hundred pairs of twins were left handed. He did not distinguish any group as identical twins; however, of his 63 pairs of unlike sex twins about 
seven per cent were left handed. Newman summarizes the findings of Siemons (18), Weitz (21) and Dahlberg (2) on identical twins. Of the 124 pairs of identical twins in these investigations, 16.5 per cent were left handed. Dahlberg also studied 128 pairs of dizygotic twins and found 7 per cent to be left handed. Verschuer (20) found 16 per cent of 158 identical twins left handed and 13 per cent of 76 fraternal twins. Newman found 50 per cent of his 100 identical twins showing some left handedness and 15 per cent of the 100 fraternal pairs. Only 6 per cent of the fraternal group were very positively left handed. Gesell agrees with Newman that handedness is genetically determined. The fact that left handedness is sometimes a familial trait and is so frequent in twins he finds as a basis for this theory. It seems to the writer that the theory of intrauterine position as a factor causing left handedness, is supported by the frequency of left handedness in twins, especially by the fact that dizygotic twins show a higher percentage than the population as a whole.

Resemblance of the twins in general intelligence. Tables 16 and 17 show the correlations obtained for each age group and each type of twin, in the various measures of language development and in I.Q. The Pearson produce moment correlation was used throughout. In correlations between like-sex twins a shortened method of the double entry Pearsonian correlation as developed by Goodenough ${ }^{6}$ was used.

${ }^{6}$ Goodenough, F. L., \& Anderson, J. E. Experimental Child Study p. 239-243. Century Co., 1931.
The resemblance of the twins in general intelligence $(r=+.72)$ is three to six points lower than that found by other investigators with one exception. The Wingfield data as reworked by the writer give an $r=$ +.55 for all twins which is only a little higher than the resemblance given for siblings of +.50 .

There are no consistent changes with age in this relationship. The correlation coefficient of +.85 of the two year olds is higher than the others, probably because nine of the twenty pairs of twins at this age are identical twins. The low correlation of the four year olds (+.37) appears to be due to the small distribution of the I.Q.'s $(\sigma=9.31)$. In agreement with the findings of Thorndike, Merriman, Lauterbach and Wingfield the coefficients of correlation for the older twins are not consistently greater than those for the younger twins.

The identical twins show a very close resemblance in general intelligence as shown by the correlation coefficient of +.92 . Wingfield found a correlation coefficient of +.90 for this relationship and the writer of +.84 on Wingfield's data. The likesex fraternal and unlike-sex groups show coefficients of +.61 and +.73 respectively. In the Wingfield data as reworked, these coefficients are +.21 and +.29 . In both instances these appear to be reversed, since like-sex twins as a rule show closer resemblance than twins of unlike sex. This may be due in part to the smaller distribution of I.Q.'s in the case of both like sex fraternal groups. Why the Wingfield coefficients fall so far below that expected for twins is hard to determine. The sampling 
DAY: Development of Language in Twins

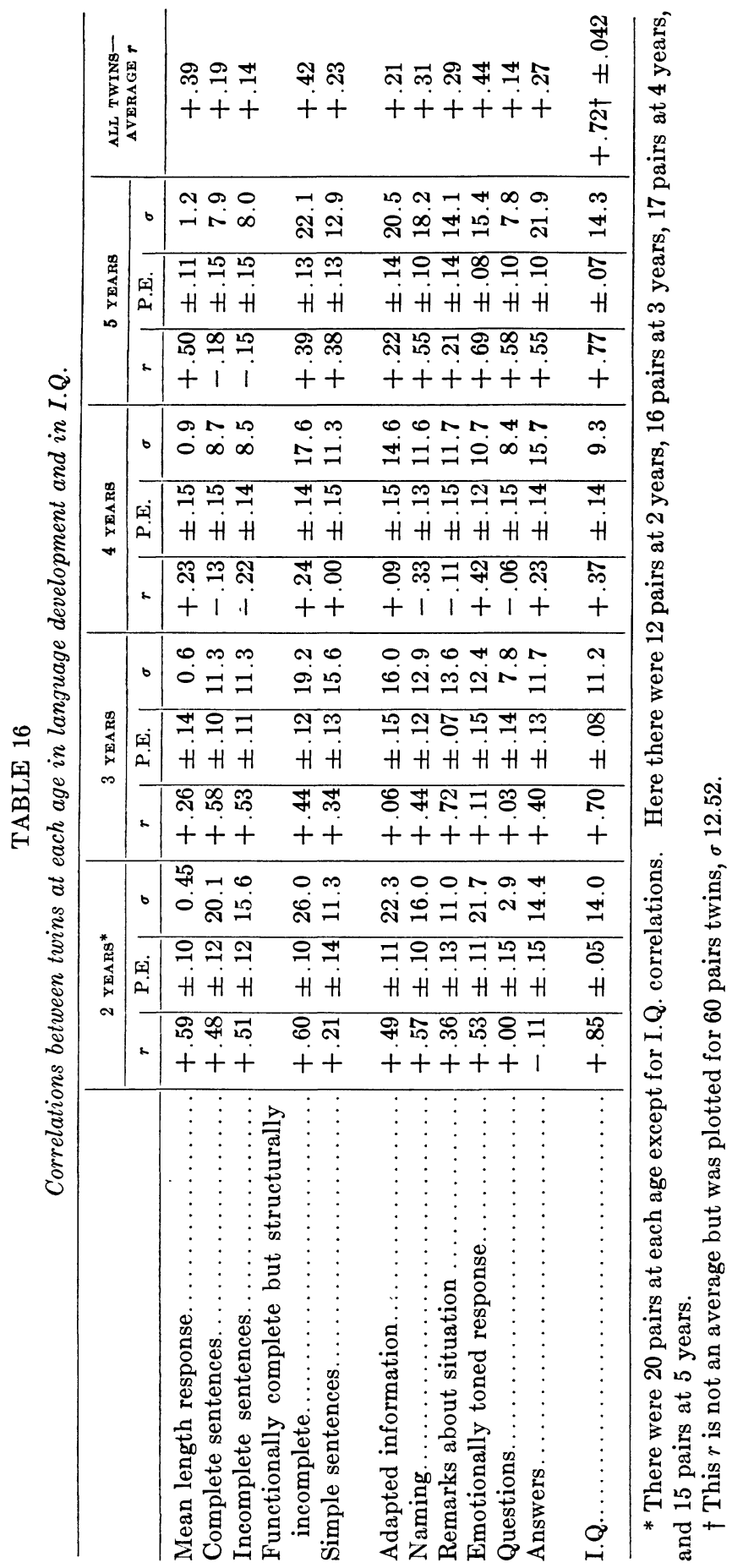




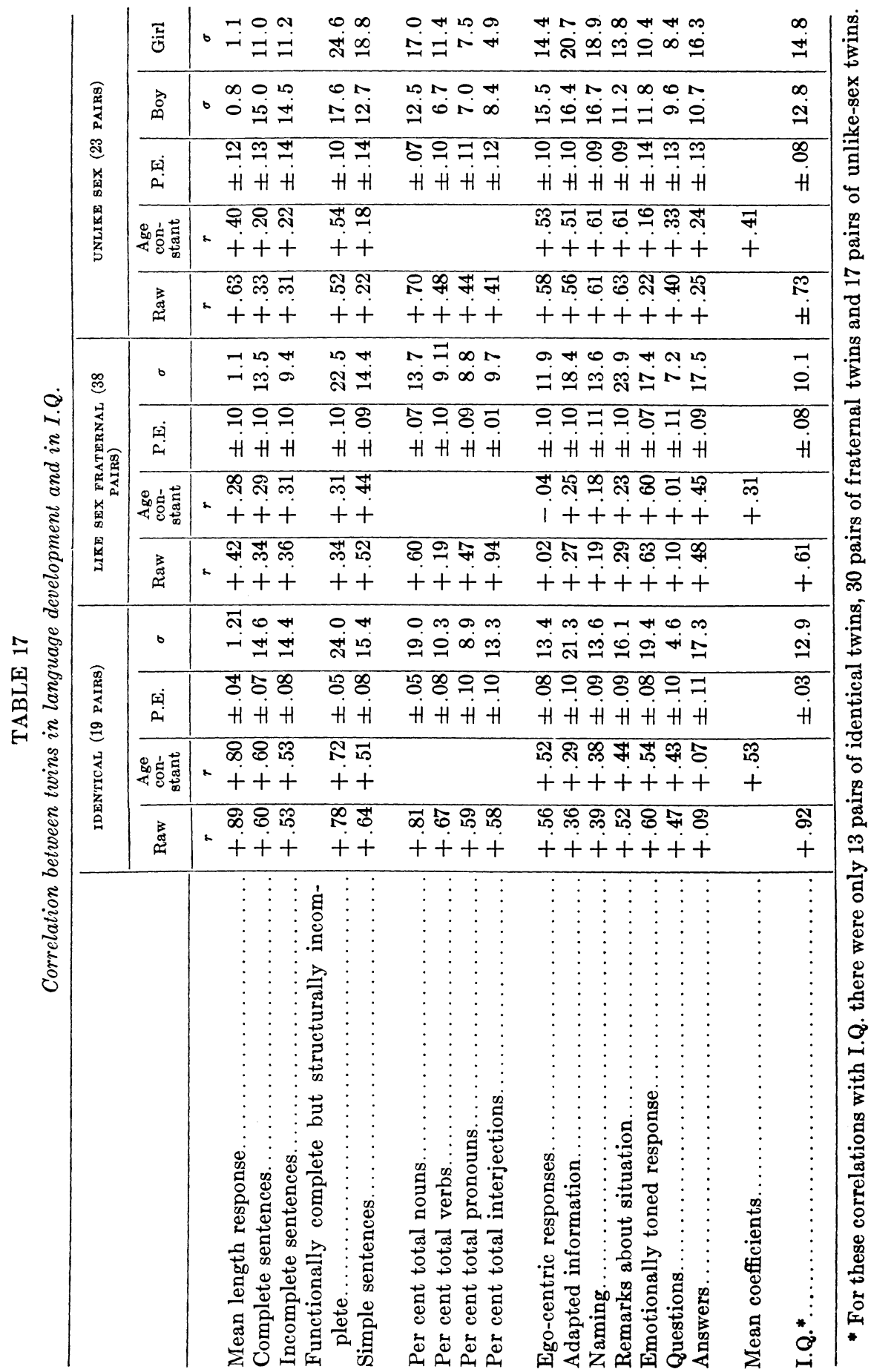


is relatively small, however, in all of these groups both in the Wingfield investigation and the present investigation.

The mean difference in I.Q. between the various twin groups is shown in Table 18.

As would be expected, the pairs of identical twins show consistently less difference in I.Q. than the pairs of fraternal twins. This corresponds to their closer resemblance in physical traits. Moreover, the pairs of like sex fraternal twins show less mean difference in I.Q. than the unlike sex twins in spite of the fact that the this may be due largely to the large number of identical twins at two years. In Questions and Answers, both of which were found to increase considerably with age. Coefficients of the five year old of +.58 and +.55 show much greater relationship between the twins than those at any other age. Over the age period at which rapid change is taking place in any function, higher relations are found between the members of the pairs. In the use of complete and incomplete sentences the two and three year olds show coefficients around +.50 whereas a slight negative relationship appears at

TABLE 18

Mean difference in I.Q. of twins

\begin{tabular}{|c|c|c|c|c|c|c|}
\hline & \multicolumn{2}{|c|}{ DAY } & \multicolumn{2}{|c|}{ WINGFIELD (178) } & \multicolumn{2}{|c|}{ NEWMAN (114) } \\
\hline & $\begin{array}{l}\text { Number } \\
\text { of pairs }\end{array}$ & $\begin{array}{c}\text { Mean } \\
\text { difference, } \\
\text { I.Q. }\end{array}$ & $\begin{array}{l}\text { Number } \\
\text { of pairs }\end{array}$ & $\begin{array}{c}\text { Mean } \\
\text { difference, } \\
\text { I.Q. }\end{array}$ & $\begin{array}{l}\text { Number } \\
\text { of pairs }\end{array}$ & $\begin{array}{c}\text { Mean } \\
\text { difference } \\
\text { I.Q. }\end{array}$ \\
\hline Identical........... & 13 & 3.46 & 45 & 6.23 & 50 & 5.3 \\
\hline Like sex fraternal. & 30 & 6.83 & 76 & 8.5 & & \\
\hline Unlike $\operatorname{sex} \ldots \ldots \ldots \ldots \ldots \ldots \ldots \ldots$ & 17 & 10.18 & 26 & 12.0 & & \\
\hline
\end{tabular}

correlation between the I.Q.'s of unlike sex twins is greater than that between like-sex fraternals. This emphasizes the fact that correlations based upon different dispersions of measures are not comparable. It will be remembered that this like-sex group had a smaller standard deviation than the unlike sex group.

Resemblance of the twins in measurements of language development. When considered from the standpoint of age groups, the correlation coefficients present negative, zero and positive relationships. In general the two year old group show the higher correlations and, as in the case of the I.Q.'s, four and five years. There is not sufficient consistency in the changes of these correlation coefficients from age to age to show either that the twins grow more or less alike with age or even that their resemblance remains about the same.

The resemblance between twins of each type in measures of language development are also quite variable. In mean length of response and the phases of the construction of sentence analysis and word analysis with the exception of the percentage of interjections, identical twins show a consistently higher correlation than do the fraternal groups. In the functional 
analysis, however, this is not true. In fact, with two exceptions (emotionally toned responses and answers) the unlike-sex group show closer resemblance. The phases of the functional analysis, because they are functional in nature might be expected to show less relationship between members of a pair than those, such as the phases of the construction analysis, which are of a developmental character.

The unlike-sex group show a correlation coefficient higher than the likesex fraternal group in the functionally complete but structurally incomplete responses, the percentage of total nouns and percentage of total verbs. They show closer resemblance than either the like-sex fraternals or the identical group in ego centric responses, adapted information, naming, and questions. In all of these phases, however, the unlike-sex group show a larger distribution of measures, than the other groups, which in part will account for this.

The average resemblance in these measures of language development for identical twins is +.53 , for likesex fraternal twins, +.31 and for the unlike sex twins +.41 .

Relation of certain environmental factors to the language development of the twins. An effort was made to find out how frequently stories were read or told to the twins in order to see if this affected in any way their language development. The estimate the mother made as to the frequency of reading stories was, of course, very rough. These estimates grouped themselves into four categories as follows:- the children were read to daily, several times a week, occasion- ally or not at all. Eighty-five per cent of the two year olds were not read to at all, as compared with 45 per cent of the three year olds, 15 per cent of the four year olds and 10 per cent of the five year olds. Since it seemed probable that the frequency of reading stories was related primarily to occupational status, occupational class was held constant in a correlation between frequency of reading stories and the mean length of response. A correlation coefficient of +.56 between frequency of reading stories and mean length of response was reduced to $+.02 \pm .533$ when occupational class was partialed out. It becomes very evident with this zero correlation that frequency of reading stories had no relationship to mean length of response but was related to the occupational status of the family.

The effect of the imitation of the language of the twins, by other members of the family, on language development was determined by means of a bi-serial correlation between imitation of speech and mean length of response. In this instance, the imitation of speech could be grouped readily only into two categories: the cases that were imitated and those that were not imitated. The bi-serial $r$ coefficient is -.35 showing a negative relationship between these two variables. This is in agreement with the popular belief that the imitation of the child's language is undesirable from the standpoint of the best language development. Moreover, in the twin situation, it only adds to the disadvantage resulting from the twins imitating each other. In approximately 33 per cent of the cases it was 
reported that members of the family imitated the speech of twins.

\section{Twinning in the ancestry}

The information obtained in regard to twinning in the ancestry was not sufficiently specific to show exact relationships. Of the 68 pairs of twins from whom this information was obtained, 68 per cent had relatives who were twins; 26 per cent on the mother's side, a similar percentage on the father's side, and 16 per cent had twin relatives on both sides of the family. There was no striking difference in this respect between identical and fraternal twins with the exception that more of the former had twin relatives on both sides of the family (33 per cent). These data are based on so few cases, however, that such a difference is probably due to selection. Moreover, since comparable data for the general population are not available the significance of these percentages is highly uncertain.

\section{SUMMARY}

The results of these data may be summarized as follows:

1. Twins are below average in intelligence test performance. The 568 pairs of twins represented by the Merriman, Lauterbach, Freeman, Wingfield and present study had a mean I.Q. of 96.3 .

2. Fraternal twins were found to be from 2 to 7 points below identical twins in general intelligence in the Merriman, Freeman, Wingfield and present investigations.

3 . The language retardation of the twins did not reduce the total test score of the intelligence test. When the mean score on the verbal test items of the intelligence tests of the twins was compared with that of the control group they were found to be equal.

4. The language retardation of the twins in terms of "language quotient" is very much greater than is their retardation in general intelligence in terms of I.Q.

5. Identical twins were found to resemble one another much more closely than fraternal twins. A correlation coefficient of +.92 was found for identical twins in general intelligence as compared with +.61 and +.73 for the like-sex and unlike-sex fraternal twins. The mean coefficient of correlation for the identical twins in the various phases of language development was +.53 as compared with +.31 and +.41 for the like-sex and unlike-sex fraternal twins.

6. In agreement with the other studies the older twins showed about the same resemblance in the traits measured as the younger twins.

7. The twins of the present study, on the average, began to talk 1 month later than their older siblings.

8. They were not found to be retarded in age of beginning to walk or in the appearance of the first tooth, when compared with norms for the general population.

9. Twenty-one per cent of the group showed a tendency to be left-handed. This is similar to the findings of other studies of twins.

10. Sixty per cent of the twins differed emotionally although only 32 per cent of the identical twins were thought to differ in this respect.

11. In 75 per cent of the twin pairs, 
1 was thought to be the leader. In unlike-sex pairs the girl was thought to be the leader twice as often as the boy.

\section{REFERENCES}

(1) Capper, Aaron: The fate and development of the immature and of the premature child. Part 1. Amer. J. of Diseases of Children, 1928, 35, no. $2,262-288$.

(2) Dahlberg, G.: Twins births and twins from a hereditary point of view. Stockholm, 1926.

(3) Davenport, C. B.: Heredity of twin births. Proc. Soc. Exp. Biol. and Med., 1920, 17, 75-77.

(4) Galton, F.: Inquiries into human faculty. History of twins, 1883, pp. 216-243.

(5) Gesell, Arnold: Mental and physical correspondence in twins. Scientific monthly, 14, 305-344.

(6) Gesell, Arnold: The mental growth of the pre-school child. N. Y. MacMillan Co., 1925, pp. 447.

(7) Gesell, Arnold: Infancy and human growth. N. Y. MacMillan Co. 1928. 418. pp.

(8) Goodenough, Florence L.: The Kuhlman-Binet tests for children of preschool age. A critical study and evaluation. University of Minnesota Press, 146 pp.

(9) Goodenough, F. L., Foster, J. C., and Van Wagenen, M. J., Minnesota preschool scale. Minneapolis Educational Test Bureau Inc.

(10) Grant, J. R.: A child's vocabulary and its growth. Ped. Sem., 1915, 22, 183-203.

(11) Haggerty, M. E., and Nash, H. B.: The mental capacity of children and paternal occupation. J. Educ. Psych., 1924, 15, 559-572.

(12) Lauterbach, C. E. Studies in twin resemblancess. Genetics, 1925, 10, $525-568$.

(13) McCarthy, Dorothea A.: The language development of the preschool child. University of Minnesota, Institute of Child Welfare Monograph Series No. 4, Minneapolis, University of Minnesota Press, 1930, pp. 174.

(14) Merriman, Curtis: The intellectual development of twins. Psych. Rev. Monog., 1924, 33, no. 5, 1-58.

(15) Muller, H. J.: Mental traits und heredity. J. hered., 1925, 16, 433448.

(16) Newman, H. H.: Studies of human twins. II. Asymmetry reversal of mirror imaging in identical twins. Biol. Bull., 55, no. 4, 298-315.

(17) Newman, H. H.: The biology of twins. Univ. of Chicago, Science Series, 1917, 185 pp.

(18) Sremons, H. W.: Die Bedeutungs der Zwillingspathologie fur die aetiologische Forschung elautert und Beispeil der Linkhanddigkeit. Setzungsber. 1. Ges. f. Morph. u. Physiol. in Munich. Jhg. 35.

(19) Thorndike, Edward L.: Measurements of twins. Archives of Philosophy, Psychology and Scientific Methods. No. 1, September, 1905, Columbia Univ. Contributions to Philosophy and Psychology, 13, no. $3,64 \mathrm{pp}$.

(20) Verschuer, O. von: Die vererbungsbiologische Zwillingsforschung. Ihre biologischen Grundlagen. Studien an 102 eineligen und 45 gleichgeshlechelichen zweieigen $\mathrm{Z}$ willings und an 2 Drillingspaarem. Ergebnisse der der Inneren Medizin $u$. Kinderheilk., 1927, 31, 35-120.

(21) Weitz, W. Studien an eineigen Zwillingen. Zeitsch. f. Klin. Med. Bd. 101.

(22) Wingfield, Alex H. Twins and orphans. J. M. Dent and Sons, Ltd., 1928, 127 pp. 